\title{
DETERMINATION OF THE STALING RATE OF EGYPTIAN BALADY BREAD BY USING TEXTURE PROFILE ANALYSIS (TPA): A NEW METHOD
}

\author{
Abd-El-Khalek ${ }^{\star}$ M.H., Thanaa A.M. Amer and Manal S. Helal \\ Food Technology Research Institute, Agricultural Research Center, Giza, Egypt. \\ *Corresponding author: mokhtarharb@yahoo.com
}

Received 16 September, 2019

Accepted 2 December, 2019

\section{ABSTRACT}

Texture profile analysis (TPA) was conducted on seventy balady bread samples collected from different five Egyptian governorates (i.e. Cairo, Giza, Beheira, Sharkia and Beni Suef) with the aim of developing a new and fast method to assess the staling of the Egyptian flat balady bread as a function of different TPA parameters. Results obtained from the TPA were compared against the classical Alkaline Water Retention Capacity (AWRC) method of bread staling determination over a storage period of three days. Hardness, adhesiveness, resilience and chewiness were found to increase as the storage period of bread samples increased, while cohesiveness decreased with the storage. The obtained results of TPA showed that among different TPA parameters, hardness, adhesiveness, cohesiveness and chewiness were highly correlated with the staling rate (SR) during a three days storage period with values of correlation coefficients ranging from 0.821 to 0.973 , while other TPA parameters (i.e. gumminess, resilience and springiness) were weakly correlated with the staling rate. Moreover, moisture content was linearly decreased as the storage of bread increased from 36.78 at the zero time to $33.19 \%$ at the third day. Derived mathematical models to calculate the AWRC and SR were significant and of the linear type with moisture content, time (day), hardness, cohesiveness, adhesiveness and chewiness as independent variables, with reasonable adjusted $R^{2}$ ( 0.55 and 0.41$)$, and adequate precision values (31.57 and 18.68) for AWRC and SR, respectively . Validation of the new method, as assessed by $\mathrm{t}$ test, showed that the differences between AWRC and $S R$ values obtained by our method were not significantly different $(P<0.05)$ from those of their counterparts obtained by the classical AWRC

method at the different storage times of bread. Our new method can be used as an alternative to the classical AWRC method with reliable, fast and accurate calculated values of both AWRC and SR.

Keywords: Balady bread, AWRC, Staling, Moisture, TPA.

\section{INTRODUCTION}

Bread is the staple and basic food in many countries and cultures which provides the individuals with nutrients and energy. Bread structure is unstable and undergoes a series of changes which lead to the ageing or what is called "staling". Freshly baked breads are soft, pliable and elastic, but when kept at room temperature, they stale within a few hours and become tough and rigid (Pourfarzad et al 2011; Abd-El-Khalek et al 2014; Amigo et al 2016).

Bread staling is a complicated process originating from a group of physical and chemical changes in the quality parameters of bread which results in crumb hardening, crust softening and loss of the characteristic fresh flavor of the product (Curti et al 2014; Amigo et al 2016; Al-Mahsaneh et al 2018). Staling process has been a subject of studies and research in many related aspects including mechanisms, factors (such as storage temperature, ingredients, or ingredients), and methods of measurement (Fadda et al 2014). Although extensively studied and many theories have been suggested, the mechanisms of staling have not been well clarified. However, the retrogradation of starch (a process in which disaggregated amylose and amylopectin chains in a gelatinized starch paste reassociate together) and the migration of water have been suggested by many researchers to be the most important factors responsible for the neg-
\end{abstract}


ative textural changes in bread (Fadda et al 2014; Al-Mahsaneh et al 2018; Ding et al 2019).

Different methods were found in literature to detect and assess the changes in physical and chemical changes caused by staling (Fadda et al 2014). These methods included, for instance, Alkaline Water Retention Capacity (AWRC), Texture Profile Analysis (TPA), Thermal Analysis (Ribotta and Le-Bail, 2007), calorimetric methods (PopovRaljic et al 2009), X-ray crystaography (Ribotta et al 2004), NMR spectroscopy (Curti et al 2011; Carini et al 2017) .. etc.

Among the aforementioned methods, AWRC although first time used is back to 1953 (Yamazaki, 1953), it is still well recognized as effective, widespread and valuable method to assess the staling of bread (Obadi et al 2018, Sidhu et al 1997). Actually, AWRC gives an indirect indication for the degree of starch crystallization. The higher values of AWRC are positively correlated with a gelatinized starch and freshness of bread while lower values indicate more crystallized starch and thus ageing and loss in freshness (Licciardello et al 2014).

On the other hand, TPA has also been used to provide reliable results that correlate to the changes in textural properties of bread that are associated with the staling process. Approved Method (\# 74-09.01) of AACC International was designed to assess the freshness of bread in terms of the changes in bread firmness (AACC 2010). Firmness is an important textural attribute and a key factor in bread staling. It can be defined as the resistance of the bread crumb to deformation. Assessment of the staling by textural attributes depends mainly on the degree of firmness and increase in crumbliness (Ahlborn et al 2005). Hardness, springiness and cohesiveness were found to be correlated with storage period and the aging of bread (Fiszman et al 2005; Curti et al 2014)

Balady bread is the major component of the Egyptian diet which is consumed in almost all day's meals. It is a flat double-layers round bread with a diameter of around $20 \mathrm{~cm}, 120 \mathrm{~g}$ weight and a thickness $\approx 1 \mathrm{~cm}$. it is made of a $82 \%$ extraction wheat flour with added fine bran to the base layer (100 kg of $82 \%$ extraction wheat flour produce 1024-1038 loaves). According to CAPMAS (2014), Egyptians consumption rate of balady bread is 889 loaves/person /year (which correspond to more than 2.4 loaves /person /day). Thus, the government has paid a great attention to the subsidy system of such an important commodity as a tool to support the food security for the Egyptian people.
Unfortunately, the classical method of AWRC is time and energy consuming procedure and requires the use of different laboratory equipments. Unlikely, TPA is a fast and accurate procedure which gives reliable results within a few minutes. Therefore, our study was conducted to develop a new, fast, time and energy saving method to assess the staling rate of balady bread over a storage period of three days by using Texture Profile Analysis (TPA) and correlating the results to their respective values obtained by classical AWRC method.

\section{MATERIALS AND METHODS}

\section{Balady bread samples}

Seventy samples of commercially produced balady bread loves from bakeries under the New Bread Subsidy System that is controlled by the Ministry of Supply and Internal Trade of Egypt were collected. Five Egyptian governorates were included in our study (i.e. Cairo, Giza, Beheira, Sharkia and Beni Suef). Detailed information of bread samples collection sites and sample size are shown in Table (1).

\section{Balady bread processing method}

In general, balady bread was prepared in the aforementioned bakeries according to the following procedure:

One $\mathrm{kg}$ of salt was dissolved in $50 \mathrm{~L}$ water, then $100 \mathrm{~kg}$ wheat flour (82\% extraction), $1 \mathrm{~kg}$ of compressed yeast and $12 \mathrm{~kg}$ of Sultani (prefermented dough) yeast were added and mixed together for $10 \mathrm{~min}$. An additional amount of $25 \mathrm{~L}$ of water was then added and continued mixing for another 20 minutes. The formed soft dough was left to rest for $10 \mathrm{~min}$ and then was transferred to a wooden box and was allowed to ferment for additional 30 minutes. Dough was portioned by hand to 120-130 g parts and were positioned by hand on wooden racks (covered with a layer of fine bran), and then were dusted with flour. After proofing for 30 minutes, dough pieces were dusted again with fine bran, flattened and degassed by gentle hand pressing, then were baked in a hot steel belt oven $\left(\sim 450^{\circ} \mathrm{C}\right)$ for a short period of time (1.5 $\left.\mathrm{min}\right)$.

After baking, balady bread loaves were left to cool for $1 \mathrm{hr}$ and then were wrapped in polyethylene bags at room temperature until further tests. 
Table 1. Balady bread samples collection areas

\begin{tabular}{|c|c|c|c|}
\hline Governorate & $\begin{array}{c}\text { Area } \\
\text { or } \\
\text { District }\end{array}$ & $\begin{array}{c}\text { Number } \\
\text { of } \\
\text { samples }\end{array}$ & Total \\
\hline Cairo & Maadi & 5 & \\
& Helwan & 5 & 20 \\
& El-Marg & 5 & \\
Mattariah & 5 & \\
& Giza city & 5 & \\
& Dokki & 5 & 20 \\
& Imbaba & 5 & \\
Beheira & Faisal & 5 & \\
& Damanhour & 5 & 10 \\
& Etai-Elbaroud & 5 & \\
Beni suef & Zagazig & 5 & 10 \\
& Minia EL-Qamh & 5 & 10 \\
& Beni-Suef City & 10 & 10 \\
\hline
\end{tabular}

Alkaline Water Retention Capacity (AWRC) and staling rate (SR)

Alkaline water retention capacity (AWRC) was determined according to the method of Yamazaki (1953) as modified and described by Licciardello et al (2014) as the following:

One gram of bread loaf, previously dried until constant weight, was put in $15 \mathrm{~mL}$ tubes (W1), then $5 \mathrm{~mL}$ of $0.1 \mathrm{~N} \mathrm{NaHCO}_{3}$ were added and mixed for $30 \mathrm{~s}$ and were let at room temperature for $20 \mathrm{~min}$. The slurry was centrifuged at $3000 \mathrm{rpm}$ for $15 \mathrm{~min}$, the supernatant was discarded and tubes were let drip for 10 min upside down with an inclination of $15^{\circ}$. Dried tubes were then weighed (W2). AWRC (\%) was calculated as [(W2-W1)/W1] $\mathrm{x} 100$.

Where $\mathrm{W} 1=$ weight of tube containing the dry sample; $\mathrm{W} 2=$ weight of tube containing the dripped sample. Analyses were conducted in duplicate at each day of the experimental period $(0,1,2$ and 3 days).

\section{Staling rate (SR) was calculated as follows}

\section{Staling Rate $(S R \%)=$ $\left[\left(A W R C_{0}-A W R C_{n}\right) / A W R C_{0}\right] \times 100$}

Where:

$\mathrm{AWRC}_{0}=\mathrm{AWRC}$ at zero time, and $\mathrm{AWRC}_{\mathrm{n}}=$ AWRC at a specific day of storage $(n)$

\section{Texture Profile Analysis (TPA)}

Texture Profile Analysis (TPA) was carried out by using Brookfield CT3 instrument (Brookfield Engineering Laboratories, Inc., MA 02346-1031, USA) according to the method outlined in the A.A.C.C. (2010) which was modified for use with flat bread by using a small scale holder TA-JPA fixture for punching through bread samples with maximum $12.7 \mathrm{~mm}$ diameter probe. Prior to testing, bread loaves were cut carefully into four quarters and each one was used at one of the experimental days $(0,1,2$ and 3 days) while the remaining quarter(s) were kept in polyethylene bags for further days test. Penetration was applied at two points of each bread quarter avoiding nonrepresentative areas as shown in Fig. (1). The following test settings were used:

Target $=8.0 \mathrm{~mm}$, Trigger load $=1.50 \mathrm{~N}$, Test speed $=2.00 \mathrm{~mm} / \mathrm{s}$, Return Speed $=2.00 \mathrm{~mm} / \mathrm{s}$ and \# of Cycles $=2$.

The following TPA characteristics were determined: hardness (average of two cycles), cohesiveness, adhesiveness, resilience, springiness, gumminess and chewiness as described in the operating instruction manual.

\section{Statistical Analysis}

Data obtained from AWRC and TPA tests were analyzed by Analysis of Variance using General Linear Model (GLM) procedure within a package program of Statistical Analysis System (SAS, 1999). Multiple regression analysis processes were applied to estimate the relationship between AWRC and/or SR (as dependent variables), and TPA analysis results (as independent variables). The equations correlating the variables and that will be used to calculate SR and AWRC were derived by using Design-Expert7 $\AA$ Software (StatEase Corporation, Minneapolis, MN) by using randomized historical data technique.

The new method was validated by using t-test at a significance level $(p<0.05)$ between actual values of randomly selected 3 bread samples versus the calculated values obtained by the new method (3 replicates for each sample). 

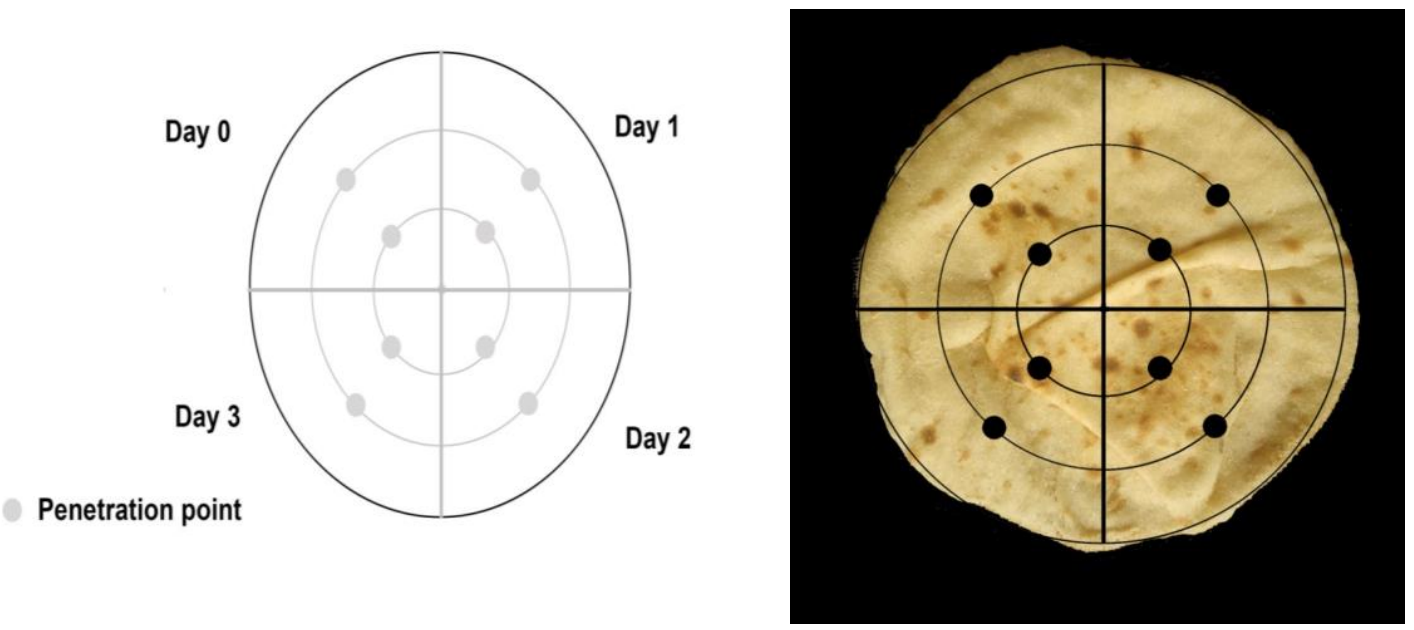

Fig.1. Balady bread probe penetration points (left: designed, right: actual)

\section{RESULTS AND DISCUSSION}

In the present study, 70 balady bread samples were collected from different governorates in Egypt with the aim of investigating the changes in alkaline water retention capacity, moisture content and texture profile analysis parameters as related to the staling rate. The obtained results were analyzed and processed statistically to obtain new equations to better understand the relationship between the different parameters and to develop a new method to determine the rate of bread staling.

\section{Moisture content, AWRC and staling rate}

Moisture content, AWRC and SR 70 balady bread samples over a storage period of three days were determined and a summary of the parameter values is shown in Table (2). The changes in the aforementioned parameters at the different storage times are illustrated in Fig. (2).

Table 2. Summary of Alkaline Water retention Capacity (AWRC\%), Staling Rate (SR\%) and moisture (\%) parameter values

\begin{tabular}{|l|c|c|c|c|c|}
\hline Parameter & N & Min. & Max. & Mean & STDV. \\
\hline AWRC \% & 70 & 173 & 311 & 228.7 & 25.4 \\
SR\% & 70 & -10.84 & 35.45 & 10.84 & 10.45 \\
Moisture & 70 & 30.96 & 39.34 & 35.37 & 1.78 \\
\hline
\end{tabular}

Generally, the average moisture content of balady bread samples was decreased as the storage time increased. Moisture content of bread samples was decreased from $36.87 \%$ at the zero time to $33.19 \%$ at the end of storage period alkaline water retention capacity was also decreased with bread storage. AWRC values were 257.93, $230.29,217.16$ and $209.24 \%$ for the storage periods $0,1,2$, and 3 days, respectively. On the opposite, and as a result of the decrease in AWRC, SR of balady bread was increased to become $18.15 \%$ at the third day of storage. The coefficient of determination $\left(R^{2}\right)$ is the percentage of the response variable variation that is explained by a linear model. Results showed that the dependent variables (i.e. moisture content, AWRC and SR) had very high values of $R^{2}$ against the independent variable (i.e. storage time). this reflects the closeness of the data to the fitted regression line indicated in Fig.(2).

Above results are in agreement with several previous studies on the changes in moisture content, AWRC and SR of bread during storage (Obadi et al 2018; Licciardello et al 2014; AbdEl-Khalek et al 2014; Elhariry et al 2011; Sidhu et al 1977; Faridi and Rubenthaler, 1984). Licciardello et al (2014) reported that a good correlation between starch retrogradation, and the overall quality of bread during ageing. It was attributed to the principle that such gelatinized starch possesses higher water-binding capacity which, conversely, decreases in crystallized starch. Thus, bread samples showed a decrease of AWRC during ageing. 


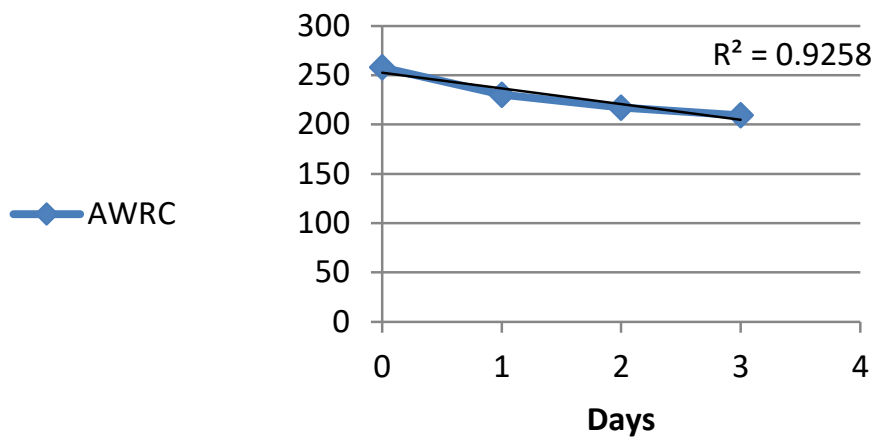

a

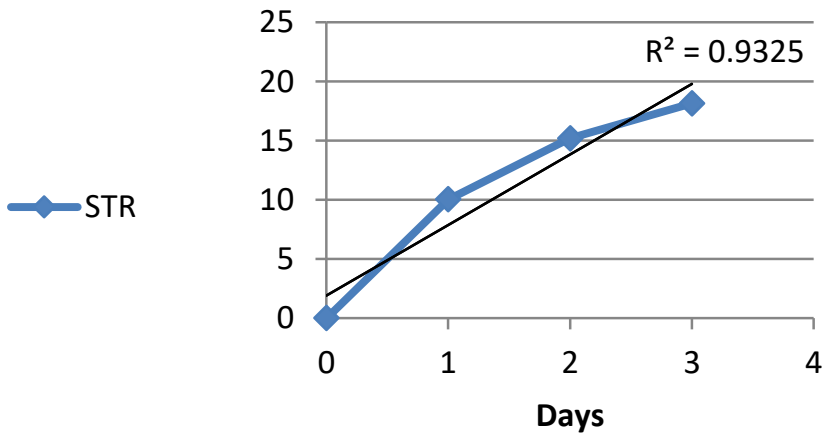

b

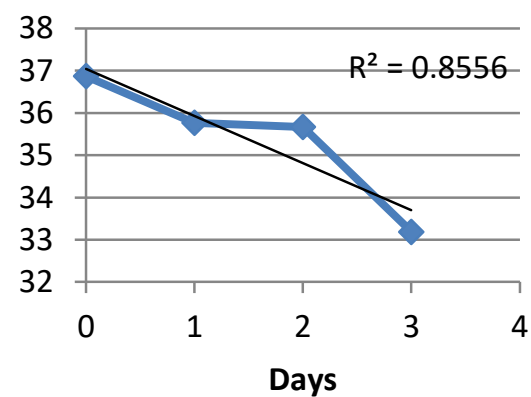

C

Fig.2. Changes in the Alkaline Water Retention Capacity (AWRC\%), Staling Rate (SR\%) and Moisture during balady bread storage period.
a) Alkaline Water Retention Capacity (AWRC\%),
b) Staling Rate (SR\%). 


\section{Texture Profile Analysis (TPA) parameters}

The changes in texture profile analysis parameters (i.e. hardness, adhesiveness, resilience, cohesiveness, springiness, gumminess and chewiness) while balady bread storage are shown in Fig. (3) while the summary of such parameter values is shown in Table (3). Hardness represents the force required to compress a food (bread) between the molars which can also be defined as force necessary to attain a given deformation. Results showed that hardness of bread was increased as the storage period increased from $43.83 \mathrm{~N}$ on average (with a minimum value of 4.23 $\mathrm{N}$ ) at the zero time to $69.83 \mathrm{~N}$ (with a maximum value of $117.58 \mathrm{~N}$ ) at the third day of storage. The same trend was observed with adhesiveness, which is the work necessary to overcome the attractive forces between the surface of the food and the surface of other materials with which the food comes into contact (e.g. tongue, teeth, palate) as it increased from $4.28 \mathrm{~mJ}$ at the zero time to $8.94 \mathrm{~mJ}$ at the end of the storage period. Chewiness, that is the energy required to chew a soild food to the point required for swallowing it, had the same positive relationship with the storage period. Contrary to that, cohesiveness had a negative relationship with the storage time as it decreased from 0.3 to 0.05 . However, the changes in other TPA parameters (i.e. resilience, springiness and gumminess) didn't show a particular trend, which reflects a poor correlation with the storage time $(r=0.73,0.42$ and -0.43 , respectively). Rasmussen and Hansen (2001) reported that bread firmness had a positive correlation with bread storage time for 3 days. Moreover, Collar and Bollain (2005) obtained high $\mathrm{R}^{2}$ values of around 0.9 between cohesiveness and bread storage time. Gómez et al (2008) reported strong correlation as a linear model between some textural properties such as firmness, cohesiveness and springiness of white bread and the storage time with $R^{2}$ values of $0.91,0.81$ and 0.90 , respectively, while other textural parameters (i.e. resilience and gumminess) had lower $R^{2}$ values ( 0.72 and 0.42 , respectively).

Correlation coefficients between experimental independent and dependent variables.

In statistics, the correlation coefficient $(r)$ measures the strength and direction of a linear relationship between two variables on a scatter plot. Correlation coefficients $(r)$ between independent variable (i.e. moisture content and TPA param- eters) and the responses (AWRC and SR) are given in Table (4). Positive correlation was observed between AWRC and moisture, cohesiveness and gumminess while this correlation was negative in case of hardness, adhesiveness, resilience, springiness and chewiness. On the opposite, SR was found to have positive correlation with hardness along with other responses with the exception of moisture content, cohesiveness and gumminess. As shown in the same table, the variables that were highly correlated $(r>0.7$ or $r<-0.7$ ) to both AWRC and SR were moisture content, hardness, adhesiveness, cohesiveness and chewiness. Both resilience and gumminess were found to be moderately correlated with AWRC and SR, whereas the correlation was very weak in case of springiness.

For the purpose of deriving equations to calculate the SR as a function of the changes in moisture content and TPA parameters, independent factors which showed high correlation coefficient (i.e. moisture content, hardness, adhesiveness, cohesiveness and chewiness) were adopted to be used.

These results regarding the relationship between moisture content, TPA parameters (e.g. hardness and cohesiveness) and SR are in accordance with those obtained by Rasmussen and Hansen (2001), Gómez et al (2008), and Curti et al (2014). Additionally, and in line with our findings, Fiszman et al (2005) also pointed out that the 'springiness' parameter did not provide information of any great value when studying the staling of bread.

\section{AWRC and SR calculation equations as a func- tion of time, moisture content and to TPA pa- rameters}

With the aim of developing a new method to determine the SR of Egyptian balady bread, water content and TPA parameters with high correlation coefficient to the staling were used to derive a mathematical equation to calculate the $\mathrm{SR}$ as a function of these parameters (Table 5).

For AWRC, the suggested model was of linear type. The model F-value of 58.24 implies the model is significant at $(P<0.01)$ meaning that there is only a $0.01 \%$ chance that a "Model F-Value" this large could occur due to noise. A significant F-test indicated that the observed $\mathrm{R}$-squared is reliable and is not a spurious result of oddities in the data set. 


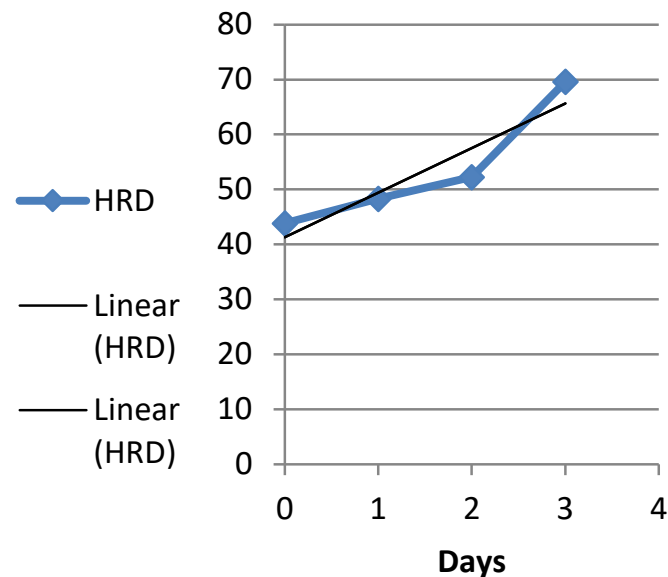

a

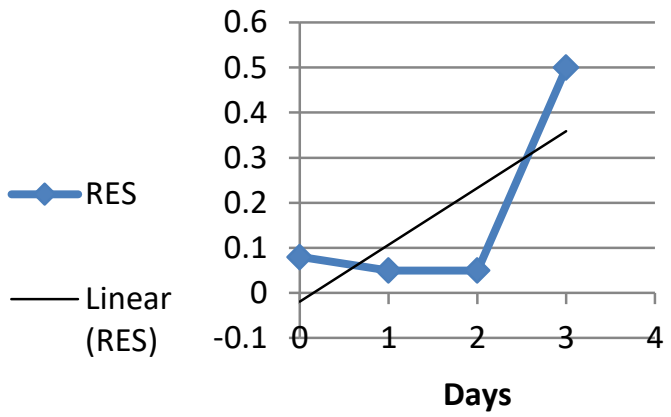

C

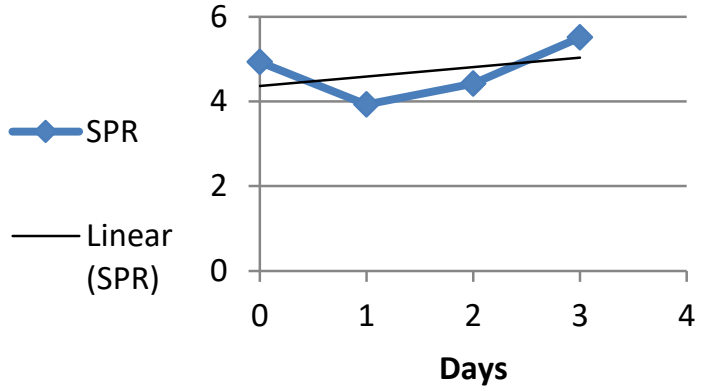

e

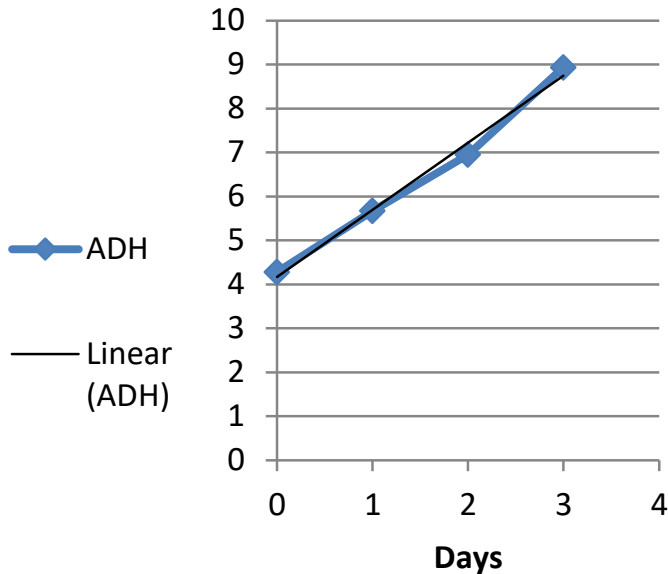

b

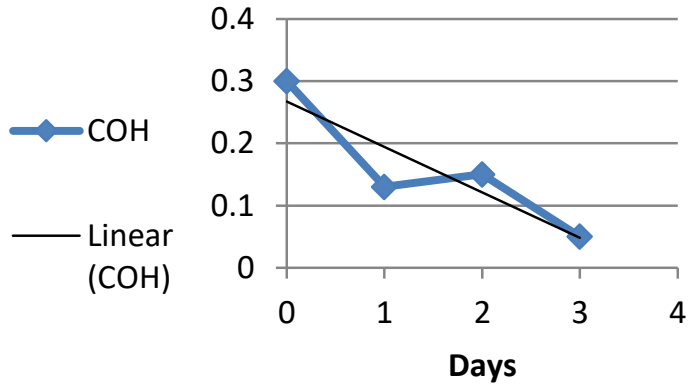

d

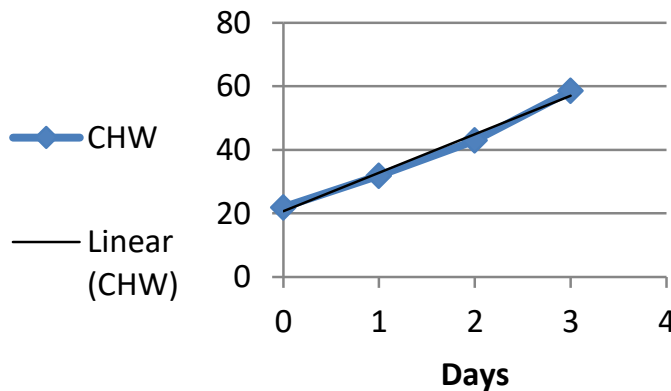

f

Fig. 3. Changes in Texture Profile Analysis (TPA) parameters during balady bread storage period.

a) Hardness, b) Adhesiveness, c) Resilience, d) Cohesiveness, e) Springiness, f) Gumminess, g) Chewiness. 
Table 3. Summary of Texture Profile Analysis (TPA) parameter values

\begin{tabular}{|c|c|c|c|c|c|}
\hline Parameter & N & Min. & Max. & Mean & STDV \\
\hline HRD (N) & 70 & 4.23 & 117.58 & 53.48 & 19.82 \\
ADH (mJ) & 70 & 0 & 34.3 & 6.46 & 4.93 \\
RES & 70 & 0 & 0.3 & 0.056 & 0.068 \\
COH & 70 & -0.08 & 0.82 & 0.18 & 0.16 \\
SPR (mm) & 70 & 0 & 11.56 & 4.70 & 2.26 \\
GUM & 70 & -1.61 & 50.38 & 9.03 & 8.89 \\
CHW (mJ) & 70 & -0.07 & 336.6 & 38.8 & 53.50 \\
\hline
\end{tabular}

\section{Where:}

$\mathrm{HRD}=$ Hardness, $\mathrm{ADH}=$ Adhesiveness, $\mathrm{RES}=$ Resilience, $\mathrm{COH}=$ Cohesiveness, SPR $=$ Springiness, $\mathrm{GUM}=\mathrm{Gum}-$ miness, $\mathrm{CHW}=$ Chewiness.

Table 4. Correlation coefficients between experimental independent and dependent variables

\begin{tabular}{|c|c|c|c|}
\hline \multicolumn{2}{|c|}{} & \multicolumn{2}{c|}{ Dependent variables } \\
\cline { 3 - 4 } & & AWRC\% & SR\% \\
\hline \multirow{4}{*}{$\begin{array}{c}\text { Independent } \\
\text { variables }\end{array}$} & Moisture & $\mathbf{0 . 8 3 7}$ & $\mathbf{- 0 . 8 4 0}$ \\
& HRD & -0.816 & 0.821 \\
& ADH & -0.937 & 0.941 \\
& $\mathrm{COH}$ & -0.556 & 0.562 \\
& $\mathrm{SPR}$ & -0.162 & 0.175 \\
& $\mathrm{GUM}$ & 0.660 & -0.648 \\
& $\mathrm{CHW}$ & -0.931 & 0.935 \\
\hline
\end{tabular}

Where:

AWRC = Alkaline Water Retention Capacity, SR = Staling rate, $\mathrm{HRD}=$ Hardness, $\mathrm{ADH}=$ Adhesiveness, RES $=\mathrm{Re}$ silience, $\mathrm{COH}=$ Cohesiveness, SPR= Springiness, GUM= Gumminess, $\mathrm{CHW}=$ Chewiness.

The predicted $R^{2}$ of 0.54 is in reasonable agreement with the adjusted $R^{2}$ of 0.55 . Adequate precision measures the signal to noise ratio where ratio greater than 4 is desirable. Our ratio of 31.56 indicates an adequate signal, thus, the AWRC model can be used to navigate the design space.

With regard to SR, the linear model type was also adopted with F-value of 32.92 that was significant at $(P<0.01)$ level. Also, predicted $R^{2}$ value was in agreement with its adjusted $\mathrm{R}^{2}$ counterpart ( 0.40 and 0.41 , respectively) with an acceptable value of adequate precision (18.68).

These results are supported by "calculated (predicted) vs. actual value plot" that is shown in Fig. (4). For AWRC, horizontal axis (X) presented the actual values while calculated ones were represented on the vertical axis (Y). Most AWRC calculated vs. actual points as illustrated in Fig. (4a) were close to the fitted line, with narrow confidence bands which reflects more model fitness. Few points with further distances were observed near the maximum and minimum ends of the line. The same observation was noticed in case of SR (Fig. 4b) with more points scattered from the fitted line.

a
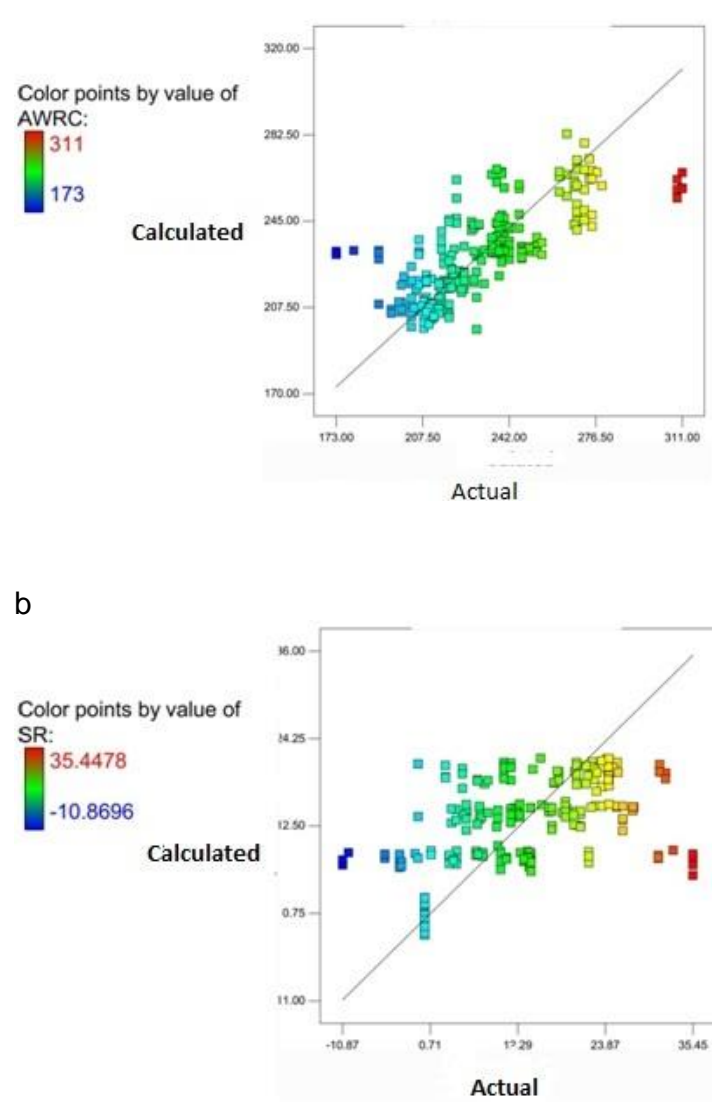

Fig. 4. $A W R C \%$ and $S R \%$ calculated vs. actual values plot.

Where: $\mathrm{AWRC}=$ Alkaline Water retention Capacity, $\mathrm{SR}=$ Staling Rate 
Table 5. AWRC and SR calculation equations as a function of time, moisture content and to TPA parameters

\begin{tabular}{|c|c|c|c|c|c|c|c|}
\hline & \multirow[b]{2}{*}{ Equations } & \multicolumn{6}{|c|}{ Model } \\
\hline & & Type & $\begin{array}{c}\text { Adjusted } \\
\mathbf{R}^{2}\end{array}$ & $\begin{array}{l}\text { Predicted } \\
\mathbf{R}^{2}\end{array}$ & $\begin{array}{l}\text { Adequate } \\
\text { Precision }\end{array}$ & $\begin{array}{c}\text { F- } \\
\text { Value }\end{array}$ & $\begin{array}{l}\text { p-value } \\
\text { Prob>F }\end{array}$ \\
\hline AWRC \% & $\begin{array}{c}267.87202-(12.75744 \text { * } \\
\text { Day })-(0.78029 * \text { Moist })+ \\
(0.081151 * \mathrm{HRD})- \\
(0.32979 * \mathrm{ADH})+ \\
\left(56.71653{ }^{*} \mathrm{COH}\right)- \\
(0.12323 * \mathrm{CHW}) .\end{array}$ & Linear & 0.55 & 0.54 & 31.57 & 58.24 & $<0.0001$ \\
\hline SR\% & $\begin{array}{c}3.08970+(6.19603 \text { * Day })+ \\
(0.042659 * \text { Moist })- \\
(0.023519 * \mathrm{HRD})- \\
(0.21145 * \mathrm{ADH})-(4.44416 \\
\left.{ }^{*} \mathrm{COH}\right)+(0.00938 * \mathrm{CHW})\end{array}$ & Linear & 0.41 & 0.40 & 18.68 & 32.92 & $<0.0001$ \\
\hline
\end{tabular}

Day $=$ storage period $(0,1,2$ or 3 in case of AWRC, and 1,2 or 3 in case of SR), Moist. $=$ Moisture content $(\%)$, $\mathrm{HRD}=$ Hardness $(\mathrm{N}), \mathrm{ADH}=$ Adhesiveness $(\mathrm{mJ}), \mathrm{COH}=$ Cohesiveness and $\mathrm{CHW}=$ Chewiness $(\mathrm{mJ})$.

However, the obtained equations were characterized by a good fitness to entry data and appropriateness for being used to calculate both AWRC and SR.

\section{Validation of the new method}

The aim of validating a new analytical method is to demonstrate that the method is suitable for the intended use with the intention of providing the scientific evidence that the analytical method is reliable and consistent before it can be used in routine analysis of product (Belouafa et al 2017). To determine if the alternative method mean is not statistically different from the reference method mean, a one way analysis of variance or a paired $t-$ test is performed (NATA, 2012).
Means of AWRC and SR of three randomly selected bread samples, determined by using old (actual values) and our TPA-based new method (calculated values) over a storage period up to 3 days, are shown in Table (6). Results showed no significant differences in AWRC means between the two methods as determined by t-test with an accuracy level ranging from -12.7 to $7.8 \%$. The only exception for that was with bread sample \#1 at the third day of storage. However, the same sample didn't show significant difference between actual and calculated SR values. In case of SR, all means of were not significantly different between the two methods in all bread samples at the different storage times. Reasonable accuracy of SR between the two methods (ranging from -12.3 to $18.77 \%$ ) was observed with some exceptions, but still non-significant, at early storage times. 
Table 6. Validation of the new method by using t-test

\begin{tabular}{|c|c|c|c|c|c|c|c|}
\hline & \multirow{2}{*}{ Day } & \multicolumn{6}{|c|}{ AWRC (\%) } \\
\hline & & Actual & Calculated & Accuracy (\%) & t-value & $p$-value & Significance * \\
\hline \multirow{4}{*}{ Sample \#1 } & 0 & 284.57 & 262.33 & 7.8 & 1.31 & 0.13 & NS \\
\hline & 1 & 247.33 & 251.67 & -1.8 & -.045 & 0.34 & NS \\
\hline & 2 & 204.33 & 214.67 & -5.1 & -1.29 & 0.13 & NS \\
\hline & 3 & 201.67 & 222.67 & -10.4 & -.2 .22 & 0.05 & $\mathrm{~S}$ \\
\hline \multirow{4}{*}{ Sample \#2 } & 0 & 273 & 256.67 & 6.0 & 2.09 & 0.05 & NS \\
\hline & 1 & 249 & 254.67 & -2.3 & -0.72 & 0.26 & NS \\
\hline & 2 & 219 & 226.33 & -3.3 & -0.71 & 0.26 & NS \\
\hline & 3 & 191.67 & 215.33 & -12.3 & -1.82 & 0.07 & NS \\
\hline \multirow{6}{*}{ Sample \#3 } & 0 & 271.97 & 261.67 & 3.8 & 0.96 & 0.19 & NS \\
\hline & 1 & 240.33 & 246.67 & -2.6 & 0.28 & 0.40 & NS \\
\hline & 2 & 215.67 & 227.33 & -5.4 & -0.88 & 0.21 & NS \\
\hline & 3 & 192 & 216.33 & -12.7 & -1.84 & 0.07 & NS \\
\hline & Dav & \multicolumn{6}{|c|}{ SR (\%) } \\
\hline & Day & Actual & Calculated & Accuracy (\%) & t-value & $p$-value & Significance * \\
\hline \multirow{4}{*}{ Sample \#1 } & 0 & - & - & - & - & - & - \\
\hline & 1 & 6.0 & 7.92 & -32.0 & -0.89 & 0.21 & NS \\
\hline & 2 & 14.8 & 13.2 & 10.8 & 0.52 & 0.31 & NS \\
\hline & 3 & 18.7 & 14.68 & 21.5 & 1.04 & 0.18 & NS \\
\hline \multirow{4}{*}{ Sample \#2 } & 0 & - & - & - & - & - & - \\
\hline & 1 & 3.23 & 6.7 & -107.4 & -0.91 & 0.21 & NS \\
\hline & 2 & 14.83 & 14.73 & 0.7 & 0.08 & 0.47 & NS \\
\hline & 3 & 21.8 & 21.1 & 3.2 & 0.56 & 0.30 & NS \\
\hline \multirow{4}{*}{ Sample \#3 } & 0 & - & - & - & - & - & - \\
\hline & 1 & 6.77 & 7.6 & -12.3 & -0.15 & 0.44 & NS \\
\hline & 2 & 20.97 & 18.77 & 10.5 & 1.82 & 0.07 & NS \\
\hline & 3 & 23.5 & 21.3 & 9.4 & 0.48 & 0.33 & NS \\
\hline
\end{tabular}

Where:

AWRC $=$ Alkaline Water retention Capacity, SR= Staling rate $(\%)$

* Significance is at $p<0.05$ level.

\section{CONCLUSION}

In our present study, a new TPA-based method was developed to determine the extent of the staling of Egyptian balady bread. The new method depends on the use of mathematical equations to calculate the AWRC and SR of bread as a function of the changes in TPA parameters (i.e. hardness, adhesiveness, cohesiveness and chewiness). All calculation equations were of the first order (linear) type with a good fit to data set and acceptable adjusted and predicted $\mathrm{R}^{2}$ values. Our new TPAbased method is much faster, energy saving and of good accuracy when compared to the old AWRC method. Validation test showed that the new method can be confidently used to determine both AWRC and SR of the Egyptian balady bread. Further studies can be carried out in many areas including the use of such method to assess AWRC and SR of Egyptian balady bread being processed under different conditions, bread fortification, and staling retardation studies.

\section{REFERENCES}

AACC 2010. Approved Methods of Analysis of AACC International. $11^{\text {th }}$ ed., St. Paul, Minnesota, USA.

Abd-El-Khalek M.H., Abd El-Kader M.H. and Elkholany E.A. 2014. Modeling of the changes in freshness, microflora and sensory attributes of Egyptian balady bread stored under different temperatures. Middle East J. Applied Sci., 4(3), 674-683.

Ahlborn G.J, Pike O.A., Hendrix S.B, Hess W.M. and Huber C.S. 2005. Sensory, mechanical, and microscopic evaluation of staling in lowprotein and gluten free breads. Cereal Chem. 8(3), 328-335. 
Al-Mahsaneh M., Aljarrah M., Rababah T. and Alu'datt M. 2018. Using of MR_FTIR and texture profile to track the effect of storage time and temperature on pita bread staling. J. Food Quality (Hindawi). 2018(1), 1-9.

Amigo J.M., Alvarez A.O., Engelsen M.M., Lundkvist $H$. and Engelsen S.B. 2016. Staling of white wheat bread crumb and effect of maltogenic $\alpha$-amylases. Part 1: Spatial distribution and kinetic modeling of hardness and resilience. Food Chem. 208, 318-325.

Belouafa S., Habti F., Benhar S., Belafkih B., Tayane S., Hamdouch S., Bennamara A. and Abourriche A. 2017. Statistical tools and approaches to validate analytical methods: methodology and practical examples. Int. J. Metrol. Quality Eng. 8(9), 1-10.

Central Agency for Public Mobilization and Statistics (CAPMAS) 2014. A study on subsidized balady bread in Egypt. Cairo, Egypt (Arabic reference). pp. 1-88.

Carini E., Curti E., Fattori F., Paciulli M. and Vittadini E. 2017. Staling of gluten-free breads: physic-chemical properties and H NMR mobility. Eur. Food Res. Technol. 243(5), 867-877.

Collar C. and Bollain C. 2005. Impact of microbial transglutaminase on the staling behaviour of enzyme-supplemented pan bread. Eur. Food Res. Technol. 221(3-4), 298-304.

Curti E., Bubici S., Carini E., Baroni S. and Vittadini E. 2011. Water molecular dynamics during bread staling by nuclear magnetic resonance. LWT-Food Sci. Technol. 44,854-859.

Curti E., Carini E., Tribuzio G. and Vittadini E. 2014. Bread staling: effect of gluten on physicchemical properties and molecular mobility. LWT-Food Sci. Technol. 59(1), 418-425.

Ding S., Peng B., Li Y. and Yang J. 2019. Evaluation of specific volume, texture, thermal features, water mobility, and inhibitory effect of staling in wheat bread affected by maltitol. Food Chem. 283, 123-130.

Elhariry H.M., Mahmoud R.M., Hassan A.A. and Aly M.A. 2011. Development of co-culture sourdough systems for improving bread quality and delaying staling. Food Biotechnol. 25(3), 252-272.

Fadda C., Sanguinetti A.M., Del Caro A., Collar C. and Piga A. 2014. Bread staling: updating the view. Cmperhensive Rev. Food Sci. Food Safety, 13,473-492.

Faridi H.A. and Rubenthaler G.L. 1984. Effect of baking time and temperature on bread quality, starch gelatinization, and staling rate of Egyptian balady bread. Cereal Chem. 6(2), 151-154.
Fiszman S.M., Salvador A. and Varela P.2005. Methodological development in bread staling assessment: application to enzymesupplemented brown bread. Eur. Food Res. Technol, 221, 616-623.

Gómez M., Oliete B., Pando V., Ronda F. and Caballero P.A. 2008. Effect of fermentation conditions on bread staling kinetics. Eur. Food Res. Technol. 226, 1379-1387.

Licciadello F., Cipri L. and Muratore G. 2014. Influence of Packaging on the quality maintenance of industrial bread by comparative shelf life testing. Food Packagaing and Shelf-life, 1, 19-24.

National Association of Testing Authorities (NATA) 2012. Guidelines for the validation and verification of quantitative and qualitative test methods. Technical Note 17. Australia.

Obadi M., Zhu K., Peng W., Sulieman A.A., Mahdi A.A., Mohammed K. and Zhou H. 2018. Shelf life characteristics of bread produced from ozonated wheat flour. J. Texture Stud., 49(5), 492-502.

Popov-Raljić J.V., Mastilović J.S., LaličićPetronijević J.G. and Popov V.S. 2009. Investigations of bread production with postponed staling applying instrumental measurements of bread crumb color. Sensors, 9(11), 8613-8623.

Pourfarzad A., Khodaparsat M.H.H., Karimi M., Mortazafi S.A., Davoodi M.G., Sourki A.H. and jahromi S.H.R. 2011. Effect of polyols on shelf-life and quality of flat bread fortified with soy flour. J. Food Process Eng., 34, 14351448.

Rasmussen P.H. and Hansen A. 2001. Staling of wheat bread stored in modified atmosphere. LWT-Food Sci. Technol. 34(7), 487-491.

Ribotta P.D., Cuffini S., León A.E. and Añón M.C. 2004. The staling of bread: an X-ray diffraction study. Eur. Food. Res. Technol. 218,219-223.

Ribotta P.D. and Le-Bail A. 2007. Thermophysical assessment of bread during staling. LWT-Food Sci. Technol. 40, 879-884.

Sidhu J.S., Al-Saqer J. and Al-Zenki S. 1997. Comparison of methods for the assessment of the extent of staling in bread. Food Chem. 58(1-2), 161-167.

Yamazaki W.T. 1953. An alkaline water retention capacity test for the evaluation of cookie baking potentialities of soft winter wheat flours. Cereal Chem. 30, 242-246. 


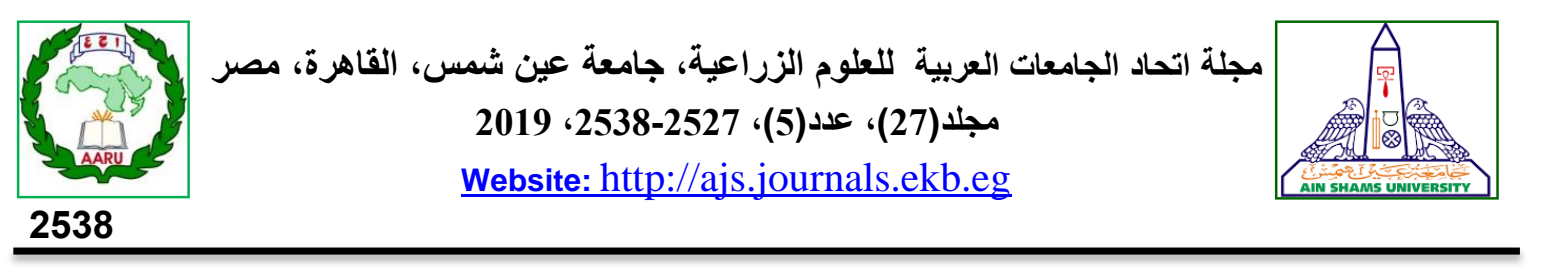

تقدير معدل البيات فى الخبز البلدى المصرى بإستخدام تحليل صفات القوام : طريقة جديدة

[200]

$$
\text { مختار حرب عبد الخالق" - ثناء عبد السلام محمد عامر - منال صبرى هلال }
$$

*Corresponding author: mokhtarharb@yahoo.com

Received 16 September, 2019

Accepted 2 December, 2019

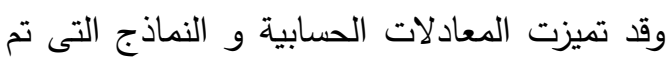

إشتقاقها فى هذه الطريقة الجديدة لحساب كل من القدرة

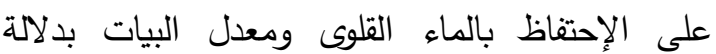

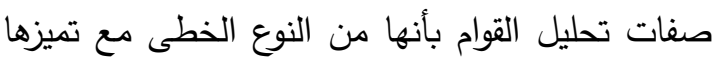

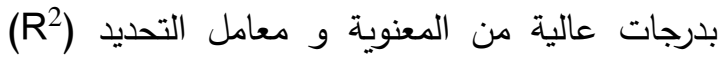

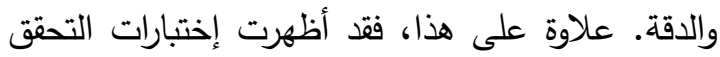

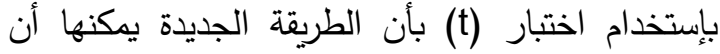

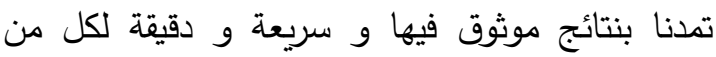
صفات القدرة على الإحتفاظ بالماء القلوى ومعدل

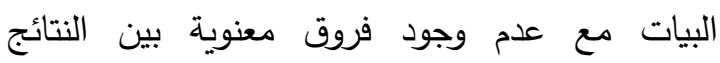

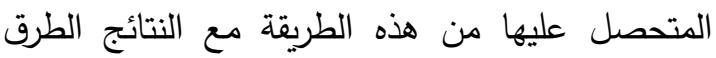

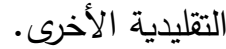

الكلمات الادالة: الخبز البلدى، القدرة على ربط الماء

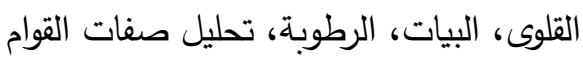

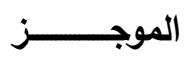

تم فى هذه الدراسة إجراء تحليل لصفات القوام على الصى

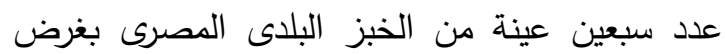

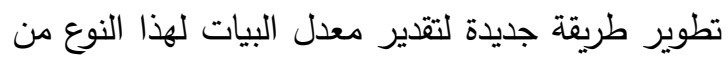

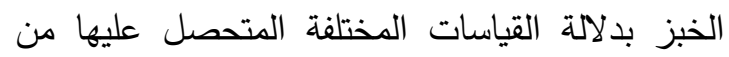
تحليل صفات القوام، وقد تمت مقارنة نتائج صفات تحليل القوام المتحصل عليها مقارنة بطريقة تقليدية

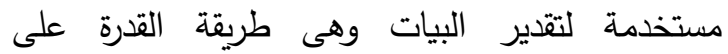
الإحتفاظ بالماء القلوى. وقد أظهرت النتائج انه توجد

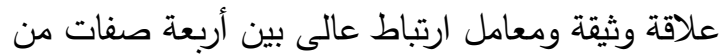

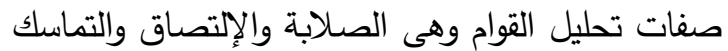

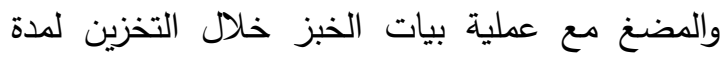
ثلاثة أيام، علاوة على ذلك فقد انخفض المحتوى

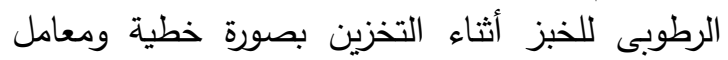

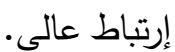

